\title{
Sobre a arquitetura teórica do Serviço Social... ... entre transgressões e demarcações de fronteiras disciplinares
}

\author{
On the theoretical architecture of Social Work ... \\ ... between transgressions and demarcations of disciplinary boundaries
}

Karin Böllert

Werner Thole*

\begin{abstract}
Resumo: Karin Böllert e Werner Thole em seu texto fazem uma reflexão sobre o processo empírico-reflexivo de construção de teoria no Serviço Social vinculado à "teoria da práxis". As práticas, o enquadramento organizacional, a perspectiva dos destinatários bem como os efeitos e efeitos colaterais do Serviço Social profissional podem ser assim captados empiricamente e contextualizados teoricamente. Eles não tentam avaliar o processo de construção da teoria segundo formas convencionais de teorização, mas defendem um processo específico de construção da teoria em Pedagogia Social através da modelagem de uma cultura de pesquisa independente. Essa cultura de pesquisa sociopedagógica tem como tema de sua reflexão tanto o processo de construção da teoria como a prática sociopedagógica. As reflexões sobre a "teoria sociopedagógica da práxis" são explicitadas com base nas perspectivas de pesquisa "Serviço Social como construção de bem-estar" e "Etnografia da práxis e de práticas sociopedagógicas". Os autores constatam que o processo de construção da teoria coloca o Serviço Social no centro do interesse empírico devido aos processos de ajuda, formação e educação concretamente realizados.
\end{abstract}

Palavras-chave: Teoria da práxis. Processos de construção da teoria. Pedagogia social. Serviço Social. Práticas empírico-reflexivas.

\footnotetext{
* Karin Böllert é doutora em Pedagogia pela Universidade de Bielefeld (Alemanha), catedrática para educação de adultos na Universidade de Münster (Alemanha); suas áreas de interesse são: desenvolvimento de teoria em Pedagogia Social, Serviço Social, políticas sociais, profissões e assistência a crianças e jovens $<$ kaboe@uni-muenster.de $>$. Werner Thole é livre-docente em Pedagogia Social, catedrático de Serviço Social com ênfase em educação não formal na Universidade de Kassel (Alemanha); suas áreas de interesse são: questões teóricas e da profissão em Pedagogia Social, teoria e práxis na assistência a crianças e jovens, educação não formal e juventude <wthole@uni-kassel.de>. Tradução do alemão: Emil A. Sobottka.
}

\begin{tabular}{|l|l|l|l|l|l|}
\hline Civitas & Porto Alegre & v. 13 & n. 3 & p. $458-476$ & set.-dez. 2013 \\
\hline
\end{tabular}




\begin{abstract}
The "theory of practice" formulated by Karin Böllert and Werner Thole calls for an empirically-reflexive theory formation process of social work, which contextualizes the current processes of transformation of the society. Research based questions can operationalize what effects and side effects of professional and disciplinary social work can be captured empirically and theoretically. It doesn't attempt to measure the theorizing process to conventional forms of theorizing, but it calls for a specific social-pedagogy theory formation process by forming an independent research culture. This social-pedagogy research culture has both as its subject of research: the theory-building process and the social-pedagogy practice. The reflections on a socialpedagogy "theory of practice" are exemplified on the research perspectives "Social work as a welfare production" and "ethnography of social work practices". They point out, that the theory-building process puts the social-pedagogy in the center of empirical interest because of the specifically implemented educational processes.
\end{abstract}

Keywords: Theory of practice. Theory formation process. Social pedagogy. Social work. Empirically-reflexive practices.

\title{
Introdução: questionamento e colocação do problema
}

$\mathrm{O}$ título do presente artigo sugere por um lado que não haveria uma arquitetura teórica do Serviço Social, ${ }^{1}$ mas pelo menos a possibilidade de sua formulação. Isto em si não é surpreendente, porquanto há quase duzentos anos existe uma variedade de sugestões para explicação e elucidação conceituais sobre como o fenômeno do "serviço social" pode ser concebido. Assim há - pelo menos implicitamente - uma multiplicidade de planos paralelos e parcialmente sobrepostos para o desenvolvimento de uma teoria do Serviço Social. Presumivelmente, há muitos outros desses planos em forma rudimentar, fragmentária, inéditos ou apenas parcialmente publicados. Algumas dessas arquiteturas no entanto encontraram seus lugares e foram traduzidas em projetos teóricos em locais específicos (cf. Niemeyer, 1998; Hamburger, 2003; May, 2008). Por outro lado, o subtítulo "entre transgressões e demarcações de fronteiras disciplinares" remete ao fato que no canteiro de obras da teoria do Serviço Social de modo algum há consenso. O terreno para o desenvolvimento da teoria parece não estar de todo medido e cartografado com precisão; ele parece ser um espaço com fronteiras ainda imprecisas. Isso não é surpreendente quando se leva em consideração as atuais discussões sobre o estatuto disciplinar, subdisciplinar ou trans e interdisciplinar do campo de pesquisa sobre o Serviço Social.

\footnotetext{
N. T. Foi tentado distinguir o Serviço Social e a Pedagogia Social enquanto disciplinas, grafando-as em maiúscula, das atividades correlatas, grafadas em minúscula.
} 
Se olhamos para trás, veremos que, na historiografia predominante relativa ao contexto alemão, o desenvolvimento do campo de pesquisa sobre o serviço social e a história de seus antecedentes se apresentam de modo relativamente claro e conciso. Sua explicitação teórica está baseada em primeiro lugar na reflexão de impulsos advindos da reforma social burguesa de meados do século 19 e, em segundo lugar, nos impulsos trazidos pelo movimento de mulheres burguesas, bem como numa reflexão sobre a situação social, econômica e cultural no final do século 19. Num segundo olhar, no entanto, esse processo de desenvolvimento aparece muito mais complexo e complicado, especialmente quando se pergunta pelas questões e perspectivas centrais das diferentes teorias e conceitos que estão escondidos nestas raízes históricas do Serviço Social. Se for dado crédito às reconstruções históricas disponíveis, então são retrospectivamente realçados pelo menos dois contextos de discussão relativos a questões do Serviço Social, de contornos distintos e inicialmente bem desconexos (cf. Rauschenbach e Züchner, 2005; Gängler, 1995). A primeira vertente da tradição está vinculada mais ou menos estreitamente com os discursos pedagógicos e filosóficos que contribuíram para o desenvolvimento da Educação como uma ciência autônoma. Segundo esta perspectiva, Johann Heinrich Pestalozzi é visto como o "fundador da pedagogia social moderna em termos de aprendizagem social, em contraste com a pedagogia individual fundada por Jean-Jacques Rousseau (1712-1778)" (Herrmann, 1992, p. 1500). Hans Thiersch (1996, p. 7) inclusive vê a ideia de uma pedagogia social "fundamentalmente e até hoje esboçada na obra de Pestalozzi". Independente de se concordar ou não com essa avaliação, há um consenso geral que Pestalozzi foi um dos primeiros que procurou comunicar o pensamento educacional moderno juntamente com a concepção tradicional da ajuda aos pobres não só em termos práticos, mas também com um embasamento teórico. Foi também ele quem primeiro conectou sistematicamente a concepção tradicional de "assistência" com as questões da "educação" e da "formação", para assim explicitar a íntima conexão entre "a questão social e a questão da verdadeira formação humana" (Kerschensteiner, 1932, p. 4). A segunda vertente da tradição na história da teoria do Serviço Social é encontrada nas reflexões iniciais da economia política e na concepção de uma ciência da assistência no estado de bem-estar social a ela vinculada. As raízes desta tradição da teoria do Serviço Social mais orientada à assistência social também vêm do século 19 e estão intimamente associadas com as reflexões apresentadas por Johann Hinrich Wichern (1808-1881).

Se simplificarmos um pouco e desconsiderarmos as sobreposições parciais, então podem ser identificadas inicialmente duas tradições teóricas 
(Rauschenbach e Züchner, 2005, p. 147; cf. Mühlum, 1981; Gängler, 1995; Niemeyer, 1998): uma que se inspira nas ciências humanas e destaca aspectos educacionais como uma forma essencial de intervenção, que está localizada na Educação e se apresenta como a vertente da Pedagogia Social, e outra, que destaca padrões de atuação relacionados ao bem-estar e à assistência como principal forma de intervenção, e salienta que a ajuda implicada no sistema de bem-estar deve ser realizada prioritariamente focada no indivíduo. Tendo como referência essas duas vertentes da tradição, dentro do Serviço Social estabeleceram-se em meados dos anos 1950-1960 na República Federal da Alemanha uma corrente "sociopedagógica" e outra "socioassistencial". Essas duas variantes do Serviço Social se consolidaram apesar de alguns considerações paralelas - passivas de serem lidas como objeções (cf. Otto e Utermann, 1971; Kappeler, 1974) - sobre o estabelecimento de diferentes formas de qualificação acadêmica, sobre a substituição legal do conceito de assistência (Fürsorge, latim: procurare) pelo conceito de serviço social (ver Gängler, 1995, p. 79), bem como sobre a reiterada e crescente associação individual das pessoas na história da teoria a uma das duas facetas do Serviço Social. A favor de uma diferenciação entre Serviço Social e Pedagogia Social, em perspectiva histórica, só testemunha a gênese dos campos de trabalho e de atuação do serviço social. Segundo o quadro aqui traçado sobre a história do desenvolvimento paralelo da teoria e da profissão, as raízes do Serviço Social podem ser encontradas no surgimento da assistência às famílias, aos jovens e às crianças, assim como da assistência social em geral e do cuidado clássico com a saúde e o bem-estar. Em contraposição a isso, a Pedagogia Social representa a tradição do serviço social com crianças e jovens, ou seja, do trabalho educativo com crianças e jovens fora da escola, no atendimento educacional de jovens, no serviço social relacionado ao trabalho, na educação infantil e no trabalho com as famílias. Atualmente não há argumentos suficientes para a adoção de uma distinção fundamental entre Pedagogia Social e Serviço Social.

De um modo geral, nas reflexões teóricas há consenso sobre a renúncia ao estabelecimento de uma distinção entre o Serviço Social e a Pedagogia Social, e se assume que os termos pedagogia social e serviço social não codificam disciplinas científicas de natureza distinta, campos de atuação claramente diferenciados, grupos profissionais distintos e tampouco carreiras de formação ou conteúdo distintos. A designação geralmente usada Serviço Social - que no contexto da língua alemã abrange e diz mais que o conceito inglês social work - reflete esse desenvolvimento e em geral traduz a unidade da Pedagogia Social com o Serviço Social (cf. Mühlum, 1981; Niemeyer, 2001; Thole, 2005). No entanto, até agora permanece incerto quais seriam os conceitos 
chave e os objetos empíricos que poderiam dar à teoria do Serviço Social uma legitimidade como área científica independente. Para alguns, os conceitos centrais advêm das exigências da atuação prática com as quais o Serviço Social se vê confrontado. Assistência, educação, apoio, aconselhamento e educação, por exemplo, se colocam então como termos centrais. Para outros, os conceitos centrais resultam de um diagnóstico de análise social e das tarefas daí resultantes para o Serviço Social. A questão social em geral, a pobreza e os problemas sociais, questões relativas à adolescência e à socialização, as competências e recursos disponíveis em cada situação para criar projetos e gerenciar a vida, assim como as expectativas sociais de normalidade e os requisitos funcionais daí resultantes para o serviço social como um assistência e controle surgem então como os objetos e temas centrais do processo de construção de teoria. Tendo em vista esta observação, é possível constatar que o processo de construção de teoria em pedagogia social não pode se referir a um lugar profissional ou disciplinar central, universalmente aceito. Questões teóricas relativas à pedagogia social atualmente podem ser encontradas e são de fato discutidas em pelo menos quatro lugares (cf. Thole, 2005). Nos países de língua alemã, um primeiro lugar disciplinar da discussão teórica pode ser encontrado na Educação; um segundo lugar - autônomo em termos disciplinares, mas formalmente não demarcado - da formulação de teoria é constituído pela "Ciência do Serviço Social"; uma terceira localização resulta do serviço social que se estende pelo conjunto das ciências sociais como um projeto interdisciplinar; e um quarto modelo migra entre os universos disciplinares, articula-se por vezes de modo mais criativo-artístico, às vezes mais terapêuticaempaticamente e outras vezes mais criticamente, e prefere essencialmente uma tradição que pressupõe que a prática do serviço social necessitaria apenas teorias adequadas ao trabalho, mas de modo algum necessitaria um processo desenvolvido e empiricamente fundado de construção de teoria (cf. Thole, 2005). Mas a partir dessa descrição de modo algum se pode concluir que inexistam propostas para uma definição teórica do Serviço Social. Além de considerações programáticas mais ou menos inspiradas no respectivo espírito de época, estão disponíveis projetos respeitáveis e bem elaborados de teoria (cf. Mollenhauer, 1964; Rössner, 1973; Winkler, 1988; Sünker, 1989), um número grande de conceitos teóricos, principalmente vinculados ao campo de atuação (cf. Thiersch, 1992; Böhnisch, 1997; Staub-Bernasconi, 2007; Otto e Ziegler, 2008), e introduções teóricas consideráveis (cf. Röhrs, 1968; Niemeyer, 1998; Hamburger, 2003; May, 2008). A variedade impressionante e respeitável de projetos teóricos, que no entanto apresentava conceitos básicos bastante díspares, levou Hans Thiersch e Thomas Rauschenbach, já no início da década 
de 1980, a desistir de incrementar sua revisão panorâmica do desenvolvimento e da teoria do Serviço Social com uma proposição alternativa própria. Ao invés disso, eles identificam os elementos estruturais para uma tal teoria. Segundo eles (Thiersch e Rauschenbach 1984, p. 984), com base numa visão teórica sobre a sociedade, uma teoria complexa do Serviço Social deve descrever e refletir sobre o mundo vivido dos seus destinatários sociopedagógicos, a função social, o enquadramento institucional e organizacional, o agir profissional bem como o caráter científico do Serviço Social. Uma concepção de pesquisa em Pedagogia Social que seguisse essa indicação, ao lado das constatações conceituais, normativas e éticas poderia diferenciar então entre as perspectivas disciplinar, organizacional, profissional, dos colaboradores, dos destinatários, da oferta de serviços e do campo de trabalho (cf. Flösser et al., 1998).

As reflexões trazidas neste texto pretendem vincular-se a este estado da arte do debate sobre a teoria da Pedagogia Social e aos problemas e desafios evocados nessa revisão muito focada e condensada. Queremos propor para a discussão reflexões sobre a elaboração de uma "teoria da práxis" com contornos sociopedagógicos. ${ }^{2}$ A base dessas reflexões, trazidas no final do texto, é formada por projetos de pesquisa desenvolvidos nos últimos anos e por conceitos desenvolvidos para esta finalidade, com que nos ocuparemos a seguir.

\section{O olhar pesquisador como base do desenvolvimento da teoria - sondagens exemplares}

Estruturalmente, um processo de construção de teoria empiricamente informado e reflexivamente fundamentado parece com maior probabilidade ser capaz de contextualizar o vocabulário básico da mudança social atualmente em curso, para operacionalizá-lo em questões de pesquisa e não apenas focalizar os sucessos, mas também dar conta empírica e teoricamente dos efeitos e dos efeitos colaterais do projeto global disciplinar e profissional da Pedagogia Social. A nova forma de construção de teoria que assim se constitui, portanto, não se centra - e aqui reside outra vantagem sobre outros projetos de teoria apenas sobre a estrutura semântica de um edifício teórico coerente. O projeto de Pedagogia Social embasado na modelagem de uma cultura específica de pesquisa se torna, nesta perspectiva, indutor e ponto de cristalização do processo de construção da teoria do Serviço Social e, em sentido inverso, esse mesmo processo e a práxis sociopedagógica tornam-se objetos da pesquisa.

Agradecemos sinceramente a Fabian Kessl por suas sugestões e discussão crítica de uma primeira versão deste texto. 


\section{O serviço social como uma produção de bem-estar - exemplo 1}

Dada a expansão das áreas de ação e das tarefas da Pedagogia Social, coloca-se a questão sobre o que constitui o núcleo da ação sociopedagógica, a base comum de suas análises teóricas e de seus estudos empíricos, sem que com a resposta a essa questão se perca a diversidade das questões e dos discursos sociopedagógicos. Tendo essa preocupação como pano de fundo, um grupo de pesquisa na Universidade de Münster, Alemanha, enfoca o Serviço Social como produção de bem-estar centrado na pessoa - uma descrição das tarefas e alocação da função que, segundo a tese aqui defendida, por um lado não façam a disciplina, a profissão e a práxis da Pedagogia Social parecerem arbitrárias, mas por outro lado também façam jus à diferenciação das teorias, da empiria e da práxis sociopedagógicas do Serviço Social. "Falando em termos modernos, bem-estar significa [...] principalmente a tarefa política de estabelecer ou assegurar relações sociais nas quais os benefícios individual e coletivo não se contradigam, mas se reforcem mutuamente em termos de efeitos sinérgicos" (Kaufmann, 2005, p. 220). Decisivo para a forma de produção de bem-estar, com base em quais definições de problemas e de quais necessidades de intervenção sejam pertinentes não são em primeiro lugar os recursos econômicas disponíveis ou as necessidades percebidas publicamente. Em vez disso, os processos de reconhecimento inerentes à produção do bemestar refletem visões de mundo e normas sociais bem como ideais políticos e socioculturais abrangentes. Portanto, a pergunta "o que é reconhecido como um problema ou risco social e considerado digno de mudança e o que é considerado um problema privado que deveria ser resolvido por iniciativa própria é uma questão essencialmente política e, por conseguinte, de natureza normativa. Possíveis respostas a essa pergunta, portanto, sempre são influenciadas por e dependem de ideias contextuais sobre o que deve ser entendido por justiça social" (Bäker, 2011, p. 1406).

No que diz respeito à produção do bem-estar sob responsabilidade pública, o grupo de pesquisa distingue analiticamente entre formas impessoais e formas pessoais. Enquanto as formas impessoais da produção do bem-estar se voltam, principalmente, para a organização dos aspectos sociais - e, com isso, sobretudo aos riscos e necessidades coletivos -, o bem-estar individual dos destinatários é um ponto de fuga normativo essencial da produção de bem-estar pessoal - ou seja, da atenção aos riscos, necessidades e exigências individuais. Formas pessoais de produção bem-estar podem ser encontradas sempre ali onde as regulamentações dependem de motivações, atitudes e disposições co-produtivas de ação dos destinatários individuais. Seu campo 
de ação é ali onde está em questão a influência sobre o modo como tanto as prescrições como os recursos - no sentido de oportunidades potenciais de vida - são ou podem ser traduzidos na condução individual da vida ou em formas subjetivas de agir e viver (Böllert, 2010). De um modo geral, com isso a concepção do Serviço Social como produção pessoal de bem-estar pode estar em sintonia com conhecimentos recentes da teoria e da pesquisa organizacionais, da teoria e da pesquisa das profissões, bem como das análises e conceituações de uma concepção crítica dos destinatários e da pesquisa sobre os destinatários atualmente em constituição (Böllert, Alfert e Humme, 2013).

Característico para um Serviço Social como produção pessoal de bemestar é seu ponto de partida de um conceito institucional de organização, com o qual as organizações são tomadas como uma estrutura social abrangente, com elementos formais e informais, com características de uma orientação específica voltada a fins e uma divisão regulamentada de trabalho, bem como com fronteiras e membros claramente identificáveis da organização. Com um entendimento organizacional mais amplo que a visão da organização como sendo orientada para a ação ou para processos, no sentido de que os serviços sociais são organizados, e mais amplo que o conceito instrumental, que destaca que os serviços sociais têm uma estrutura e uma ordem, as políticas organizacionais podem ser examinadas como processos de tomada de decisão em serviços e equipamentos sociais, sobre cujo caráter político precisa ser refletido (Grunwald, 2011). Ação profissional, por sua vez, depende da existência de diferentes modos de prestação das organizações, do mesmo modo que as próprias organizações dependem da facilitação do agir profissional para a sua legitimidade (cf. Peter, 2010). Com essa perspectiva, a já clássica concepção dual, das organizações como limitantes de um lado e a profissão de assistente social por outro, é abandonada em favor de um entendimento reflexivo da profissão, com o qual os problemas estruturais na atuação do assistente social e do pedagogo social assim como o potencial da boa atuação profissional passam a estar no centro do interesse; passam a ser vistos como uma qualidade e não como disputa por exclusividade de competências (cf. Dewe e Otto, 2011). Esta concepção da atuação profissional já sugere uma determinação mais objetiva da produção de bem-estar pessoal pelo Serviço Social, que assume uma concepção dos destinatários na qual a compreensão de sujeito dos destinatários torna-se o padrão de medida da interdependência entre organização, profissão e destinatários. As concepções normativas sobre a constituição e o ordenamento da sociedade contidas no enquadramento social e político da produção pública de bem-estar são, portanto, determinantes de quem e como se tornará destinatário do serviço social. Não são quaisquer 
grupos de pessoas que se tornam grupo-alvo da forma pessoal de produção de bem-estar; ao contrário, em questão está sua constituição pelas organizações e pela profissão, e, portanto, a realimentação do conceito de destinatários pelas condições estruturais institucionalizadas no Serviço Social (cf. Bitzan e Bolay, 2011; Böllert, 2013a).

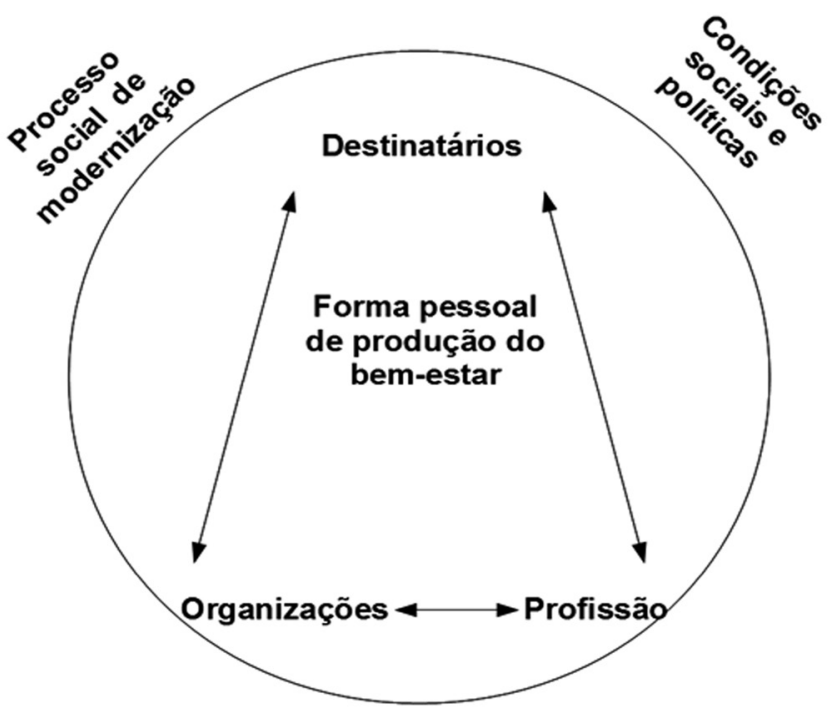

Ambientes sociais

Fig. 1. Serviço Social como produção de bem-estar (Böllert, 2013b).

Assim os processos do serviço social como uma produção bem-estar pessoal são pesquisados como uma figuração de interesses, concepções, orientações e potenciais dos destinatários, das organizações e da profissão do Serviço Social. A multiplicidade de questões de pesquisa empírica que assim surgem requer abordagens metodológicas e fundamentações teóricas diferenciadas. Com este perfil, nosso grupo de pesquisa se posiciona como parte de um projeto interdisciplinar de Serviço Social ligado às ciências sociais, mas também, ou precisamente por isso, se pergunta pelo foco compartilhado do Serviço Social na heterogeneidade das abordagens teóricas e empíricas. 


\section{Etnografia de práxis e práticas sociopedagógicas - exemplo 2}

As sociedades e os temas sociais não são dados "por natureza". A sociedade, os temas e as associações se constituem e reproduzem através de práxis no contexto das realidades dadas e possíveis, e das tradições, disposições e expectativas ali presentes, que no entanto de modo algum podem ser vistas como rígidas e imutáveis; elas são geradas e atualizadas continuamente através de práxis e práticas. Nesta perspectiva, a constituição, manutenção e reprodução da sociedade, do mundo da vida e da subjetividade dependem de atos performativos; elas têm, portanto, como base os recursos disponíveis, os processos de produção, consolidação e estabilização, de formatação e reformatação (cf. Butler et al., 1997; Reckwitz, 2006). ${ }^{3}$ Um programa de pesquisa elaborado nesta perspectiva teórica e referido às áreas de ação da Pedagogia Social e do Serviço Social tem como foco as formas, práxis e práticas da ação pedagógica e sociopedagógica. O olhar empírico capta os processos de produção e encenação de atores - a "performance" tanto dos pedagogos como das crianças e dos adolescentes, dos alunos e possivelmente também dos pais - nos projetos e cenários educacionais, tanto formais como informais, os processos de constituição e articulação de interpretações de si e do mundo, as práticas de desenvolvimento e apresentação de conhecimentos, saberes e ações, bem como a performatividade das práticas cotidianas tanto físicas como simbólico-interativas, assim como os enquadramentos e dispositivos organizacionais. Tarefa do Serviço Social não é apenas descrever estruturalmente as lógicas identificáveis em cada caso, mas também capturar as formas de produção das modalidades de práxis documentadas nessas práticas. O ganho que se obtém com um processo de geração de conhecimentos teóricos assim orientado empiricamente será indicado através de três exemplos.

1. O trabalho educativo em casas da juventude, centros comunitários, centros de juventude e instituições similares geralmente é descrito como anárquico ou caótico. Contradizendo essa visão, num projeto de pesquisa financiado pela Fundação Alemã de Pesquisa (DFG) e realizado nas universidades de Hildesheim e Kassel, na Alemanha, foi corroborada a constatação de que o trabalho com crianças e jovens se caracteriza por uma estrutura de ordem específica, reflexiva, mesmo que não presente de forma consistente. Característica especial destes

\footnotetext{
As reflexões aqui expostas se vinculam a uma "teoria da práxis" mesmo que esta "até o momento não tenha encontrado ainda uma forma definitiva e sistematizada" (Reckwitz, 2003, p. 289) e que as contribuições para uma "teoria da práxis" já disponíveis sejam composições muito diferentes entre si (cf. Hillebrandt, 2009; 2011).
} 
cenários pedagógicos constitui a autonomia do trabalho com crianças e jovens e o contraste com outras instituições e áreas de ensino e campos de ação; essa autonomia já se documenta explicitamente, entre outros, nos procedimentos de admissão. A escola, por exemplo, é controlada através de períodos regulamentados de tempo e de regras normativas, e a aquisição de conhecimento é realizada com base em processos didatizados de ensino-aprendizagem seletivos e voltados ao desempenho. $\mathrm{O}$ trabalho com crianças e jovens não pode recorrer a um enquadramento ou configuração institucional semelhante. A entrada - de "fora" para "dentro" - numa das instalações do campo de atuação sociopedagógica não desencadeia automaticamente uma transformação análoga de papéis como a entrada na escola. Crianças e jovens não precisam abrir mão de suas identidades cotidianas ao entrarem em projetos de apoio nem combiná-las com "novos" papéis; ao contrário, elas são convocadas a desempenhá-los num novo ambiente. Os fenômenos de transição - a produção de pertença e de comunidade - no trabalho com crianças e jovens de modo algum representam apenas epifenômenos que seriam paralelos a sua atividade central. Ao contrário, a conformação destes fenômenos é em si uma parte essencial daquilo que em sua heterogeneidade constitui performativamente o trabalho com crianças e jovens. No trabalho com crianças e jovens se condensa o desafio profissional de um comprometimento educativo de agir como "o outro entre iguais" e de participar neste papel na comunicação diária dos jovens. Não tematizados permanecem no entanto as regras "constitutivas", das quais três - as regras participar, estar visível e ser moderado - no projeto puderam ser identificadas como essenciais para o trabalho com crianças e jovens (cf. Cloos et al., 2009).

2. Num projeto conjunto de pesquisa na Universidade de Kassel e na Universidade de Ciências Aplicadas de Erfurt está em questão o conhecimento dos colaboradores na área educacional de creches que tenham diferentes formações. Especificamente é tentado responder a questão a que conhecimento geral, pedagógico, metodológico e disciplinar esses colaboradores recorrem na definição, modulação e fundamentação de suas práticas educativas e como eles refletem sobre elas. Entre outras coisas, é tratada nesse contexto a questão como esses colaboradores estabelecem interlocução com crianças com experiências de migração ou de famílias migrantes, como eles as apresentam e através de que recursos em conhecimento e padrões 
de interpretação é possibilitado ou facilitado o acesso e a participação dessas crianças nas ofertas de atividades da creche. A análise do material etnográfico e audiovisual mostra que as diferenças culturais que realmente importam na vida cotidiana da creche tendem a ser descritas nas reflexões dos pedagogos como sendo essenciais, através da oposição entre "alemão" e "estrangeiro", e não como sociais e, por consequência, modificáveis. A cultura não é evocada como algo fundamentalmente criado e mutável, mas como uma entidade ligada a uma determinada nacionalidade. Nas sequências de entrevistas ficou bastante evidente que os pedagogos desenvolvem uma prática sensível à questão da migração, que também foi encontrada no material de pesquisa coletado em outras instituições. Segundo as reconstruções feitas até agora, é perceptível como eles articulam uma sensibilidade para a heterogeneidade social e cultural com que se defrontam. No entanto, a pluralidade existente e percebida é reduzida numa perspectiva culturalista, definida como conjunto de características nacionais, e assim dissociada do seu processo social de produção (cf. Thole, Göbel e Milbradt, 2013).

3. No projeto de pesquisa $A$ violência familiar - rupturas e incertezas na práxis da Pedagogia Social foram analisadas as situações de risco para crianças e os procedimentos rotineiros nos serviços sociopedagógicos dos gabinetes municipais da juventude; tratou-se de identificar as construções sobre o bem-estar das crianças e sobre a violência familiar explicitadas pela linguagem e documentadas na práxis. As reconstruções feitas com base nos materiais de pesquisa mostram que os colaboradores dos gabinetes ativam individualmente sua própria forma de agir, emoldurada pelos respectivos programas e estruturas organizacionais. Além da regra prática "diagnosticar e pressionar", que se revela nas práticas interpretativas na forma de um diagnóstico bem focado, foram sistematizados outras sete regras práticas. Perceptíveis são as regras práticas da "interpretação e ação baseadas no universo cotidiano", do "intuir e tatear", do "estimular e acompanhar", do "experimentar e ensinar", da "determinação e liderança", do "esclarecer e gerir" bem como uma regra prática do "saber e profetizar". Nos gabinetes específicos de proteção à criança, essas oito regras práticas se distribuem mum leque contínuo e tenso de formas de tratamento de casos entre o deixar-e-acompanhar, verificar-e-cooperar e o saber-e-assimir (cf. Retkowski, Schäuble e Thole, 2011b; 2012b). 
Estes três exemplos mostram que por meio de estudos empíricos é possível identificar as modalidades e regras básicas de ação relacionadas ao campo de trabalho, as formas de constituição de relações de trabalho e de alianças, bem como as formas diferenciadas de construir o trabalho sociopedagógico. Também foi possível comprovar empiricamente que assumir no trabalho pedagógico profissional padrões de interpretação cotidianos e pragmáticos sem refletir o suficiente teórica e tecnicamente sobre eles pode, contra as próprias intenções, reforçar a produção de etiquetamentos. As concepções sobre organizações, atores e relacionamentos subjacentes à práxis sociopedagógica passam assim por uma elucidação reconstrutiva e empiricamente embasada. $\mathrm{O}$ olhar determinante da pesquisa e da formação de teoria, normativamente virulento, sobre a práxis educativa, o suposto conhecimento de como a ação do saber hábil deve apresentar-se, nesse caso não se encontra no início do processo empírico, mas torna-se praticamente o seu ponto focal nas reflexões e construções teóricas feitas com base no material empírico. A apreciação dos resultados da pesquisa mostra que os estudos empíricos, baseados em práticas concretas, oferecem a oportunidade de reconstruir estruturas organizacionais, modos de ação e relacionamentos como uma dimensão central, sem determinar prévia e normativamente o conteúdo do pedagógico (cf. Retkowski, Schäuble e Thole, 2012a).

\section{Por um processo empiricamente fundamentado de desenvolvimento reflexivo de teoria}

As pesquisas e os exemplos oriundos da prática acima mencionados à primeira vista de modo algum apresentam um panorama congruente. $\mathrm{Na}$ pesquisa designada como Serviço Social como produção de bem-estar e na diferenciação entre uma forma pessoal e outra impessoal de serviço social por um lado está em questão a reconstrução da constituição organizacional e profissional do Serviço Social e, por outro, a identificação das condições e modos de vida e o bem-estar dos destinatários, e, com isso, em última análise, trata-se sempre também das concepções de uma justiça social normativa e construída através de políticas públicas, representadas nas respectivas formas de apoio, dos serviços, dos benefícios e dos campos de atuação do Serviço Social. Na pesquisa sobre as práticas sociopedagógicas, ao contrário, parece que se trata prioritariamente da operacionalização de uma perspectiva de pesquisa microssociológica, com a finalidade de rastrear as sutilezas da formação do Serviço Social, para captar com precisão características e também diferenças nos campos de atuação e na práxis da Pedagogia Social através da observação das práticas de constituição do sujeito e dos relacionamentos. 
Numa apreciação mais atenta, no entanto, se revelam também pontos em comum, uma vez que as duas propostas e perspectivas de pesquisa têm por objetivo captar empiricamente as modalidades e as condições estruturais do Serviço Social, para desvelar os modelos normativos, morais e ideológicos da práxis do Serviço Social. Enquanto uma compreensão da pesquisa pretende dar conta disso através da reconstrução empírica das condições organizacionais, profissionais e de políticas de bem-estar, a outra pretende realizar isso através da reconstrução das práticas. As duas perspectivas de pesquisa reivindicam, primeiro, a pretensão de compreender os processos concretamente realizados de ajuda, educação e formação e os cenários em que os conceitos, métodos, técnicas e instrumentos assim como as interpretações e formas de apresentação da produção e reprodução do Serviço Social e a perspectiva dos destinatários acontecem, para conhecer melhor o que o Serviço Social em sociedades modernas e as formas de educação, socialização, formação, ajuda, apoio e prevenção nelas existentes significam e como se caracterizam. Com isso a totalidade da atividade da Pedagogia Social torna-se o centro do interesse empírico. Em segundo lugar, ambas perspectivas partem da convicção de que um ganho em conhecimento não pode ser conquistado através da confirmação empiricamente mascarada do sempre-já-sabido, mas tão somente através de um movimento empírico de busca. Terceiro, une-as a convicção de que através desta orientação empírica pode ser desencadeado um processo de construção de teoria empiricamente informada e reflexivamente fundamentada, que pode esclarecer a gramática fundamental das transformações sociais ora em curso. Enquanto uma teoria sociológica da práxis no fundo se concentra em esclarecer para compreender, uma teoria sociopedagógica da práxis se sente convocada a disponibilizar, ao lado do conhecimento compreensivo, também conhecimento voltado à ação, isto é, ela quer reconhecer e descrever a práxis sociopedagógica não apenas como objeto do interesse científico, mas também como um campo de possibilidades para o desencadeamento de competências para a estruturação e realização de projetos de vida através da práxis do trabalho sociopedagógico. As reflexões aqui apresentadas traçam os contornos deste modelo de teoria sociopedagógica da práxis e exemplificam como esta perspectiva teórica pode se afirmar e ser refinada empiricamente. Elas também indicam como as dimensões e facetas do Serviço Social - a observação empírica dos destinatários, suas condições e seus mundos de vida, os marcos institucionais e organizacionais em que estão inseridos, o agir profissional e as propostas metodológicas, bem como a identificação das implicações sociopolíticas e das funções sociais - não são esferas isoladas, mas, através de seu entrelaçamento e sua composição, tornam-se 
campos do conhecimento de uma teoria sociopedagógica da práxis (Thole, 2013, p. 31).

Esse entrelaçamento de esferas até então atuantes de modo isolado umas em relação às outras por fim também está em questão quando os diversos serviços dos sistemas de formação e de política social são relacionados e interconectados - e isso tanto na perspectiva de suas respectivas práticas como também na de seus ancoramentos disciplinares específicos. A partir deste pano de fundo, argumentos bem embasados empiricamente incentivam que se questione as fronteiras até agora existentes entre essas esferas. Nesse sentido o sociólogo e filósofo francês Alain Ehrenberg (2012), em seu estudo O mal-estar na sociedade, reflete sobre a transformação abrangente da relação entre indivíduo e sociedade bem como sobre a condição mental dos sujeitos e sua relação com as instituições. Tendo como base suas análises, ele defende uma interconexão mais estreita entre os arranjos governamentais, educacionais e psicoterapêuticos. Enfaticamente ele defende uma nova relação entre os serviços institucionalizados de saúde e assistência nas nações industrializadas. Segundo sua exposição, as formas psíquicas de sofrimento são praticamente inseparáveis das experiências de exclusão social e de desrespeito, e por conseguinte os serviços sociais de assistência são desafiados a se rearranjar se quiserem seguir reagindo de modo adequado às experiências, agora multicomplexas, de sofrimento dos indivíduos.

Se for dado crédito a esta análise, então por exemplo as delimitações e transições do cuidado, da educação e da formação das crianças pequenas na família e a educação infantil nas instituições respectivas necessitam ser estruturadas de modo mais aberto e flexível. Será necessário levar adicionalmente em consideração que a família é um lugar insuficientemente valorizado no tocante a sua relevância pedagógica. Debates e pesquisas atuais demonstram que as famílias têm um papel decisivo na constituição das biografias educacionais, e isso não apenas com relação à primeira infância, mas durante toda a infância e juventude. Os pais orientam, abrem espaços para o desenvolvimento e tomam decisões centrais relativas à formação (Böllert, 2012). Além disso, muitas experiências empíricas reforçam a necessidade de se conceber a passagem do ensino infantil para a educação escolar não como transposições abruptas, mas como processos gradativos de transposição de fronteiras. Com relação às transições do ensino fundamental para as outras formas de educação assim como a respeito das demarcações estruturais e escolarizadas das fronteiras há bons, embora ainda insuficientes argumentos empíricos em favor de uma simplificação e de maior fluidez. 
No entanto, a simplificação da transposição das fronteiras não deveria contribuir para o abandono das lógicas e perfis conceituais respectivos, ou para negar a especificidade das tarefas e exigências de cada ator. A socialização familiar se orienta por modalidades e práticas diferentes dos serviços institucionalizados da educação infantil. $\mathrm{O}$ mandato educacional da assistência educacional a crianças e jovens difere categoricamente daquele das escolas. O desafio portanto é relativizar a demarcação das fronteiras sem ignorar as diferenças condicionadas estrutural e funcionalmente e fundadas em concepções distintas. E esse desafio clama por respostas inteligentes.

Mas se aqui se defende uma simplificação das passagens entre os sistemas de formação e os serviços prestados pela assistência social, entre a escola e o serviço social, entre a formação continuada e as qualificações escolares ou entre os sistemas de formação profissional e as medidas de requalificação, constituindo interfaces entre eles, então parece necessário levar isso adiante não apenas no nível da práxis, mas também no nível disciplinar, reexaminando-se as demarcações de fronteiras e procurando por pontos em comum. A concepção de uma teoria da práxis de inspiração sociopedagógica convoca a refletir simultaneamente sobre a reformulação das fronteiras entre os campos profissionais e entre as especificidades disciplinares, sobre as fronteiras interdisciplinares e sobre as fronteiras intra-disciplinares nas ciências da educação. Isso não significa necessariamente derrubar as fronteiras, mas abrir passagens entre elas e procurar por possíveis sinergias; é isto que em perspectiva é constitutivo para uma teoria sociopedagógica da práxis. Esta deslimitação da formação da teoria sociopedagógica se expressa em última análise no fato que há muito tempo na investigação de questões e processos da esfera social vêm sendo acolhidas e são emprestadas contribuições das disciplinas vizinhas. "O Serviço Social age aqui como transfronteiriço para romper com as limitações de uma análise científica puramente disciplinar, com o objetivo de ampliar seu próprio campo de visão, para compreender desafios práticos com base em um apoio teórico mais amplo e para fundamentar suas pesquisas de modo conceitualmente ampliado" (Böllert, 2013a, p. 199).

\section{Referências}

BÄCKER, G. Soziale Sicherung. In: H.-U. Otto; H. Thiersch (Orgs.). Handbuch Soziale Arbeit. München: Reinhardt, 2011. p. 1406-1428.

BITZAN, M.; BOLAY, E. Adressatin und Adressat. In: H.-U. Otto; H. Thiersch (Orgs.). Handbuch Soziale Arbeit. München: Reinhardt, 2011. p. 18-24.

BÖHNISCH, L. Sozialpädagogik der Lebensalter. Weinheim: Juventa, 1997.

BÖLLERT, K. Bildung braucht viele Orte. DJI Impulse, v. 100, n. 4, p. 36-39, 2012. 
BÖLLERT, K. Soziale Arbeit als Wohlfahrtsproduktion. In: N. Oelkers; M. Richter (Orgs.). Aktuelle Themen und Theoriediskurse in der Sozialen Arbeit. Frankfurt am Main: Verlag Peter Lang, 2013a. p. 109-116.

BÖLLERT, K. Grenzenlose Soziale Arbeit: Soziale Arbeit als Grenzgängerin? In: H.-R. Müller et al. (Orgs.). Erziehungswissenschaftliche Grenzgänge: Markierungen und Vermessungen. Beiträge zum 23. Kongress der Deutschen Gesellschaft für Erziehungswissenschaft. Opladen: Verlag Barbara Budrich, 2013b. p. 197-216.

BÖLLERT, K. Einleitung: Soziale Arbeit als Wohlfahrtsproduktion. In: K. Böllert (Org.). Soziale Arbeit als Wohlfahrtsproduktion. Wiesbaden: Springer VS, 2010. p. 7-15.

BÖLLERT, K. et al. Einleitung: Soziale Arbeit in der Krise. In: K. Böllert et al. (Orgs.). Soziale Arbeit in der Krise. Wiesbaden: Springer VS, 2013. p. 7-14.

BUTLER, J. Psyche der Macht: Das Subjekt der Unterwerfung. Frankfurt am Main: Suhrkamp, 1997.

CLOOS, P. et al. Die Pädagogik der Kinder- und Jugendarbeit. 2. ed. Wiesbaden: VS Verlag für Sozialwissenschaften, 2009.

DEWE, B.; OTTO, H.-U. Profession. In: H.-U. Otto; H. Thiersch (Orgs.). Handbuch Soziale Arbeit. München: Reinhardt, 2011. p. 1131-1142.

EHRENBERG, A. Das Unbehagen in der Gesellschaft. Frankfurt am Main: Suhrkamp, 2012.

FLÖSSER, G. et al. Jugendhilfeforschung: Beobachtungen zu einer wenig beachteten Forschungslandschaft. In: T. Rauschenbach; W. Thole (Orgs.). Sozialpädagogische Forschung: Gegenstand und Funktionen, Bereiche und Methoden. Weinheim: Juventa, 1998. p. 225-261.

GÄNGLER, H. Sozialpädagogikals Wissenschaft: Studien zurWissenschaftsgeschichte der Sozialpädagogik. Dortmund (Tese de livre-docência), 1995.

GRUNWALD, K. Organisation und Organisationsgestaltung. In: H.-U. Otto; H. Thiersch (Orgs.). Handbuch Soziale Arbeit. München: Reinhardt, 2011. p. 1037-1048.

HAMBURGER, F. Einführung in die Sozialpädagogik. Stuttgart: Kohlhammer, 2003.

HERRMANN, U. Pestalozzi, Johann Heinrich. In: R. Bauer (Org.). Lexikon des Sozialund Gesundheitswesens. München: R. Oldenbourg Verlag, 1992. p. 1499-1501.

HILLEBRANDT, Fr. Praxistheorie. In: G. Kneer; M. Schroer (Orgs.). Soziologische Theorien: Ein Handbuch. Wiesbaden: Verlag für Sozialwissenschaften, 2009. p. 369394.

HILLEBRANDT, Fr. Normativität in der Praxistheorie Pierre Bourdieus. In: J. Ahrens, et al. (Orgs.). Normativität: Über die Hintergründe sozialwissenschaftlicher Theoriebildung. Wiesbaden: Verlag für Sozialwissenschaften, 2011. p. 221-239.

KAPPELER, M. Sozialpädagogik und Sozialarbeit als Funktion des bürgerlichen Staates. Erziehung \& Klassenkampf, v. 4, n. 15-16, p. 115-122, 1974.

KAUFMANN, F.-X. Sozialpolitik und Sozialstaat: Soziologische Analysen. Wiesbaden: VS Verlag für Sozialwissenschaften, 2005. 
KeRSCHENSteIneR, G. Die Prinzipien der Pädagogik Pestalozzis. PestalozziStudien, v. 2, p. 1-14, 1932.

MAY, M. Aktuelle Theoriediskurse Sozialer Arbeit: Eine Einführung. Wiesbaden: VS Verlag für Sozialwissenschaften, 2008.

MOLLENHAUER, K. Einführung in die Sozialpädagogik. Weinheim: Beltz, 1964.

MÜHLUM, A. Sozialpädagogik und Sozialarbeit: Eine vergleichende Darstellung zur Bestimmung ihres Verhältnisses in historischer, berufspraktischer und theoretischer Perspektive. (Tese de doutorado). Frankfurt am Main: Eigenverlag des Deutschen Vereins für öffentliche und private Fürsorge, 1981.

NIEMEYER, C. Klassiker der Sozialpädagogik. Weinheim: Juventa, 1998.

NIEMEYER, C. Klassiker der Sozialpädagogik. In: H.-U. Otto; H. Thiersch (Orgs.). Handbuch Sozialarbeit/Sozialpädagogik. Neuwied: Luchterhand, 2001. p. 1058-1068.

OTTO, H.-U.; ZIEGLER, H. Der Capabilities-Ansatz als neue Orientierung in der Erziehungswissenschaft. In: H.-U. Otto; H. Ziegler (Orgs.). Capabilities Handlungsbefähigung und Verwirklichungschancen in der Erziehungswissenschaft. Wiesbaden: VS Verlag für Sozialwissenschaften, 2008. p. 9-15.

OTTO, H.-U.; UTERMANN, K. (Orgs.). Sozialarbeit als Beruf: Auf dem Weg zur Professionalisierung. München: Juventa, 1971.

PETER, C. Neo-Institutionalismus und Soziale Arbeit. Zeitschrift für Sozialpädagogik, v. 8 , n. 2, p. 156-168, 2010.

RAUSCHENBACH, T.; ZÜCHNER, I. Theorien der Sozialen Arbeit. In: W. Thole (Org.). Grundriss Soziale Arbeit: Ein einführendes Handbuch. 2. ed. Wiesbaden: VS Verlag für Sozialwissenschaften, 2005. p. 139-159.

RECKWITZ, A. Grundelemente einer Theorie sozialer Praktiken: Eine sozialtheoretische Perspektive. Zeitschrift für Soziologie, v. 32, p. 282-301, 2003.

RECKWITZ, A. Die Transformation der Kulturtheorien: Zur Entwicklung eines Theorieprogramms. Weilerswist: Velbrück Wissenschaft, 2006.

RETKOWSKI, A. et al. "Diese Familie braucht mehr Druck ...": Praxismuster im Allgemeinen Sozialen Dienst - Rekonstruktion der Bearbeitung eines Kinderschutzfalles. neue praxis. Zeitschrift für Sozialarbeit, Sozialpädagogik und Sozialpolitik, v. 41, p. 485-504, 2011.

RETKOWSKI, A. et al. Zur performativen Herstellung von Subjektivität. In: B. Friebertshäuser et al. (Orgs.). Feld und Theorie: Herausforderungen erziehungswissenschaftlicher Ethnographie. Opladen: Verlag Barbara Budrich, 2012a. p. 137-152.

RETKOWSKI, A. et al. Sorgende Arrangements im Kinderschutz. In: W. Thole et al. (Orgs.). Sorgende Arrangements: Kinderschutz zwischen Organisation und Familie. Wiesbaden: VS Verlag für Sozialwissenschaften, 2012b. p. 9-15.

RÖHRS, H. (Org.). Die Sozialpädagogik und ihre Theorie. Frankfurt am Main: Verlagsgesellschaft, 1968.

RÖSSNER, L. Theorie der Sozialarbeit. Ein Entwurf. München: Reinhardt, 1973. 
STAUB-BERNASCONI, S. Soziale Arbeit als Handlungswissenschaft: Systemtheoretische Grundlagen und professionelle Praxis - ein Lehrbuch. Bern: Haupt, 2007.

SÜNKER, H. Bildung, Alltag und Subjektivität: Elemente zu einer Theorie der Sozialpädagogik. Weinheim: Deutscher Studienverlag, 1989.

THIERSCH, H.; RAUSCHENBACH, T. Sozialpädagogik: Theorie und Entwicklung. In: H. Eyferth et al. (Orgs.). Handbuch zur Sozialpädagogik-Sozialarbeit. Neuwied: Luchterhand, 1984. p. 984-1016.

THIERSCH, H. Lebensweltorientierte Soziale Arbeit: Aufgaben der Praxis im sozialen Wandel. Weinheim: Juventa, 1992.

THIERSCH, H. Sozialarbeitswissenschaft. In: R. Merten et al. (Orgs.). Sozialarbeitswissenschaft: Kontroversen und Perspektiven. Neuwied: Luchterhand, 1996. p. $1-20$

THOLE, W. Soziale Arbeit als Profession und Disziplin: Das sozialpädagogische Projekt in Praxis, Theorie, Forschung und Ausbildung - Versuch zu einer Standortbestimmung. In: W. Thole (Org.). Grundriss Soziale Arbeit: Ein einführendes Handbuch. 2. ed. Wiesbaden: VS Verlag für Sozialwissenschaften, 2005. p. 15-60.

THOLE, W. Überlegungen zu einer sozialpädagogischen Theorie der Praxis. Ein erster Aufschlag ... In: M. Schilling et al. (Orgs.). Soziale Arbeit quo vadis? Weinheim: Beltz, 2013. p. 19-36.

THOLE, W. et al. "...wir reden nicht direkt drüber, aber wir leben es..." Praxen des Umgangs mit migrationsbedingter Heterogenität und Differenz in Kindertageseinrichtungen. In: C. Berndt; M. Walm (Orgs.). In Orientierung begriffen: Interdisziplinäre Perspektiven auf Bildung, Kultur und Kompetenz. Wiesbaden: Springer VS, 2013.

WINKLER, M. Eine Theorie der Sozialpädagogik. Stuttgart: Klett-Cotta, 1988.

Autor correspondente:

Werner Thole

Arnold-Bode-Straße 10 - Raum 1302

34127 Kassel

Recebido em: 20 set. 2013

Aprovado em: 15 out. 2013 